\title{
The exploration and practice of cultivating excellent news communication talents in universities
}

\author{
Fen Tang ${ }^{1}$, Dandan Zhu ${ }^{2}$ \\ Department of Chinese language and literature, College of science and engineering disciplines, Jiangxi \\ Normal University of science and technology, Jiangxi Province, Nanchang, 330000 China
}

Keywords: Journalism and Communication, Talent training, Teaching objectives.

\begin{abstract}
Nowadays, Many of the long-standing problems in the news communication industry are emerging, and the demand for excellent talents in the news media industry is becoming increasingly prominent. Application - oriented universities should reform from the reality and explore the training channels of talents in news communication according to the needs of social development .To achieve the teaching objectives which is transfer excellence news communication talents for our society, we make an in-depth analysis of the existed problems in the teaching of news communication in universities, and put forward a method of building an excellent team of teachers to lead students to organize new media platform to collect news communication practice based on the needs of social development at present.
\end{abstract}

\section{Introduction}

The program for cultivating outstanding talents in journalism is one of the four excellence talents programs launched by the Ministry of Education. In the process of the popularization and development of modern information technology, the traditional media model gradually transitioned to the modern media model. In the transition period of the new media, the news communication industry is very urgent for the professional news communication talents. Now, most of our colleges and universities are difficult to meet the current social development needs in the professional level of journalism, which causes the problem of outstanding talents shortage is increasingly prominent[1]. In order to solve this problem as soon as possible, the colleges and universities should explore the teaching and training methods of news communication talents, formulate and implement the excellent news communication talents training plan, promote the reform and innovation of the news communication education, and thus greatly enhance the level of students' professional quality to provide comprehensive professional news communication talents for the community.

\section{The practical significance of cultivating excellent news communication talents}

Traditional news communication industry has a standardized operational processes and lines generally. The advantages of this kind of professional production mode are becoming more and more precious in the development of modern media industry. But with the rapid development of modern information technology and network, the trend of democratization swept the world. Traditional media and new media are gradually integrated. With the help of micro-blog, WeChat and other modern network channels, news and information are spread rapidly. Which has changed the pattern of the current news and communication industry to a great extent[2]. The integration of traditional media and modern media is directly related to the survival and development of the news media industry. The media integration process requires a lot of capital investment ,technical and talent support, these are the inevitable demand for the development of new media.

The rapid development of information technology has greatly promoted the reform and progress of the news and communication industry, which resulting in a huge change in the news of the 
editing and dissemination. Analyzing with our current social background, the development of the socialist market economy has promoted the new media industry transformation and expansion to a large extent. At the same time, the news extortion, false news and other chaos also occurs frequently, which causes the masses are negative of news dissemination. In addition, most of the news and communication departments in colleges and universities are generally more educated than practice in the selection of teachers. They choose elite school doctors over experienced teacher. Therefore, most young teachers are too short of post internship experience to solve unexpected problems in the process of news dissemination. The teaching process focused on the theory, and the students are lack of opportunity to practice, so it is difficult to cultivate a journalism talent with a solid foundation and experience.

\section{A probe into the training methods of talent teaching in news communication}

In order to achieve the goal of training advanced journalism and communication talents, journalism and communication majors in universities can be classified according to their achievements and professional skills. The score is relatively high and the excellent news media personnel are composed as the news dissemination talent excellence training experimental class. And cultivating students according to the direction of new media professionals [3]. At the same time, it is necessary to establish an online learning platform to integrate news and information in a timely manner, so that students can quickly find and understand news and information. Innovating the teaching methods of school-enterprise cooperation will strengthen the basic knowledge of students and gain their practical ability to shape the excellent news communication talent at the same time.

To create a professional team of news and communication professional teachers. The professionalism of journalists is largely dependent on the teacher's teaching level. Therefore, the construction of teachers' team plays a vital role in the training of journalism and communication talents. The major colleges and universities must set up a high level, high quality teachers team. At present, teachers of Journalism and communication in China's universities generally have a higher educational background and degree. They can master the rich theoretical knowledge. But their practical experience is obviously inadequate. It is difficult to teach students to solve the actual situation by their experience and methods [4]. To solve this problem, the major colleges and universities could send excellent teachers to the news organization to study, so as to accumulate the work experience of the news communication industry, improve the ability of teaching to better serve the education work. Meanwhile, the media senior practitioners are teachers who cannot be ignored. They have a wealth of work experience to solve a variety of unexpected problems quickly. Therefore, selecting journalists who have been in the news organization for many years to teach lessons as the form of lectures or concentrated lectures in department of journalism and communication. During these lectures, they can teach students valuable practice and work experience is conducive to improve the quality of journalism to help students understand the new dynamic media and improve the practical ability of students.

The reform of the teaching mode of universities journalism and communication. The major colleges and universities should carry out the reform of the teaching mode of news communication according to the actual situation of the school to achieve the teaching goal of cultivating excellent journalistic talents. They should cooperate with the needs of social development, develop excellence talents in news communication training programs which is in connection with students for the specific circumstances and professional standards. We should keep up with the pace of times, innovate the teaching mode of modernized news communication, develop students' cross-cultural communication and full media awareness, shape the comprehensive talents who meets the current development of journalism in China. In the teaching process of journalism communication, we must adhere to the guidance of Marxist ideology as the guidance of journalism communication, We must uphold the people's truth-seeking and realistic conscience and the professional qualities of the journalists in the news industry and serve the people wholeheartedly. This is the core and essence of Marxist journalism. We must deepen and innovate the news communication professional teaching system actively ,take the concept of consolidating the foundation, attention to the application, strengthen skills, set up professional teaching modules and application practice ability training courses, organize relevant teaching and practical activities [5]. 


\section{Practical project design of excellent journalism and Communication Talents}

Practice is an important part of the teaching process of Journalism and communication, and it is an important means to improve the professional operation ability of students. Therefore, colleges and universities should provide students with practical platform to ensure the construction of outstanding news talents work smoothly. Major universities should seek the support and cooperation of relevant media organizations, expand the school media cooperation teaching mode. Relevant media enterprises can reserve and cultivate talents of news communication specialty in undergraduate colleges and universities according to the results of the practice .

Expanding the practice channels of news and communication professionals. When carrying out the school-media co-teaching work, we should also use the new media practice platform to train the practice of journalism professional students [6] .Investing and building news laboratories that meet the requirements of the Excellence talents in news communication program to help students complete their practical teaching tasks. Regularly send students in the experimental class to enter the news media institutions to study and practice. In the course of practice, students should be learned to apply. Competing the assigned work and tasks using the expertise learned during the school. Students can understand and master the basic knowledge of the news communication, the working methods as workers and improve professional quality.

Developing new media communication platform. Carrying out new media training camp activities for the news media students and providing online learning exchanges and practice platform for the excellent news communication talents. Simultaneously, the major colleges and universities can invite experienced industry elite to guide students to carry out new media social networking platform practice, to provide new media training opportunities for outstanding news media and to encourage students to participate in the operation of the new media network platform. Helping journalism students understand the operation of the new media network platform. The tutor carries on the appraisal and the examination to the student's duty completion situation. And analyzes the student's problem, to help students better improve their professionalism. Carrying out internship training activities with the new media platform is helpful to achieve the goal that traditional media and new media complements advantages and shares resources. The use of new media platform to cultivate excellent news communication talents will be helpful to protect the news communication industry in the development of the tide of the healthy long-term development.

Carrying out new media practice innovation activities. With the rise of the news media, such as WeChat public number, today's headlines, etc., industry gradually into the era of media innovation. Media innovation is a kind of entrepreneurial simulation practice in the modern news communication industry. Experienced teacher organized students who has a solid foundation, outstanding skills, and with innovative thinking to carry out new media innovation practice. Also, students can choose guide teachers to participate in practice according to their own interests and expertise. The team should combine the progress of modern electronic information technology with the needs of social development to complete the media innovation project. Such as the instructor to lead the excellent news communication talents team to register the WeChat public number or client,to design the public number of the operation and the news client's promotional activities [7].

After the preparation of new media innovation practice, students are guided by the instructor to investigate and expand the innovation project. And exploring the initial feasibility of the program. After finishing the information, the students report to the instructor and instructors guide the questions through the mentor for the students to remove the potential problems in the program. In the course of practice, the instructor has to track the participation in order to answer questions for students at any time. They help students solve the sudden situation and provide reference students in time.

Finally, as the reviewers, the industry elite test and evaluate the results of the media innovation practice activities, which organized by students, by the way of competition , give the relevant guidance. In order to maximize the enthusiasm of journalism students to participate in the practice of new media innovation, improve the practical ability of excellence in news communication, media innovation and practice activities can greatly enhance the team of students in the professional ability and sense of innovation, to create a modern social development needs for excellence in news communication talents [8]. Developing new channels for the modernization of news dissemination 
to promote the orderly development of new media industry.

\section{Conclusion}

It is an important strategic decision to promote the healthy and sustainable development of socialism with Chinese characteristics. It is an important strategic decision for the development of the news communication industry in China. The core connotation and substantive goal of cultivating excellent news communication talents is to train and develop the successor of the socialist news industry with Chinese characteristics. The training of excellence in news communication must be carried out closely around the core of the people's journalists who adhere to Marxism as the core and serve the people wholeheartedly. This is the ultimate goal of excellence in news communication.

\section{Reference}

[1] Yao Daowu.Excellence in Journalism Media Education[J].Journal of West Anhui University, 2015, 31(6):148-151.

[2] Feng Xiangju.The Construction of Excellent Teaching Staff in News Communication Specialty in Local Colleges and Universities[J].Journal of Yulin Teachers College, 2016, 37(3):113-117.

[3] Zhao Lifang,Zhong jinwen,Zha ba.Persistence and Innovation: A New Approach to the Development of News Communication Education in Ethnic Universities[J].Modern Communication - Journal of Communication University of China, 2016, 38(12):141-144.

[4] YuDan,Cheng Zhiqiang,Huang Chaoqin.On the "3 + 1" Talent Training Model of Journalism- Take Zhejiang Wanli College as an example[J].Journal of Ningbo Education Institute, 2015, 17(1):1-3.

[5] Yu Keguang.Further Discussion on the Cultivation of News Communication Talents in Domestic Universities - - An Interpretation and Analysis of the "Talent Education Program for Excellence in News Communication"[J].News university, 2015 (5):126-130.

[6] Jiang Xiaoling.Exploration and Practice of the Joint Cultivation of Local Colleges and Universities under the Background of "Excellence Plan"—— Taking Hubei Radio and Television College as an Example[J]. Journal of Hubei Normal University (Philosophy and Social Sciences), 2015 (2):119-122.

[7] HuangJin, YangKun,LiYong.To build a news school The full implementation of excellence in news communication talent education training program--Exploration and Practice of Chengdu College[J].Education and Teaching Forum, 2015 (12):127-129. 